\title{
NOTAS SOBRE CIDADES MÉDIAS: uma proposta para a Bahia
}

\section{NOTES ABOUT MEDIUM CITIES: a proposal to Bahia}

\author{
Patricia Chame Dias \\ Doutoranda em Geografia pela Universidade Federal da Bahia (UFBA). Especialista em \\ Políticas Públicas e Gestão Governamental do Estado da Bahia. Pesquisadora da Superintendência de \\ Estudos Econômicos e Sociais da Bahia (SEI).patriciadias@ sei.ba.gov.br
}

\author{
Mayara Mychella Sena Araújo \\ Doutoranda em Geografia pela Universidade Federal da Bahia (UFBA). Bolsista FAPESB do Programa \\ de Pós-Graduação em Geografia da UFBA. \\ maiaraujo@yahoo.com.br
}

\begin{abstract}
RESUMO
O propósito deste artigo é estimular reflexões em torno dos termos cidade, urbano e cidade média, com vistas a propor critérios que, considerando as especificidades da rede urbana da Bahia, permitam identificar suas cidades médias. Certamente que por se tratar, ao mesmo tempo, de um debate teórico e um exercício de identificação, não se esgota aqui o tema em pauta. Com este texto pretende-se estabelecer um ponto de partida para a posterior elaboração de estudos mais aprofundados sobre tal questão e que deem conta das singularidades dessas cidades. Entende-se ainda que seus resultados podem servir de subsídio a pesquisas similares a serem realizadas em outras unidades da Federação. Inicialmente, apresentam-se algumas ideias e conceitos, postos por diferentes autores, sobre cidade e sua relação com a urbanização decorrente do processo de industrialização. Faz-se em seguida uma reflexão do tema cidade média, em que se analisam questões referentes ao tamanho demográfico como princípio para sua identificação, suas características e papéis. Partindo-se dessas considerações e da análise de algumas das peculiaridades da rede urbana do Estado, propõe-se um conjunto de critérios básicos para verificar quais de suas sedes municipais seriam assim categorizadas. Por fim, tecem-se argumentações adicionais sobre o tema, realçando a importância de estudá-lo.
\end{abstract}

Palavras-chave: Cidades médias. Cidade. Urbanização. Rede urbana. Articulação regional.

\section{ABSTRACT}

The purpose of this paper is to stimulate discussions on the terms city, urban and medium sized city, with a view to proposing criteria which, considering the specificities of the urban network of Bahia, allow to identify their medium-sized cities. Certainly because it deals, at the same time, of a theoretical debate and a mapping exercise, here does not dissipate the subject at hand. With this paper we intend to establish a starting point for the posterior elaboration of deepening studies about this question and give account of the singularities of these cities. It is understood though its results may provide of subsidies to similar researches to be conducted in other states. This work finds itself divided into four parts, and a brief introduction. Initially, we presented some ideas and concepts, made by different authors, about city and its relationship with urbanization due to industrialization. The second topic was realized a reflection of the theme medium-sized city, which reviews questions related to population size as a principle for their identification, characteristics and roles. Based on these considerations and analysis of some of the peculiarities of the urban network of state, proposed a set of basic criterions to see which of their municipal seats would be so categorized. Finally, we had woven additional discussions on this subject, highlighting the importance of studying it.

Keywords: Medium-sized cities. City. Urbanization. Urban network. Regional articulation.

Geo UERJ - Ano 15, no. 24, v. 1, $1^{\circ}$ semestre de 2013 p. 285-311

ISSN: 1415-7543 E-ISSN: 1981-9021

http://www.e-publicacoes.uerj.br/index.php/geouerj 


\section{INTRODUÇÃO}

As cidades da Bahia tem sido objeto de uma série de estudos e pesquisas elaborados nas instâncias acadêmica e de planejamento. Todavia, raramente há uma tentativa de verificar as articulações que elas estabelecem entre si e os papéis que exercem na dinâmica urbana estadual. Mais propriamente, embora se verifique certa profusão de trabalhos sobre as regiões existentes no interior do estado, em particular a formada pela metrópole, nos anos mais recentes, revelaram-se raras as análises sobre a rede urbana baiana, sendo mais comuns trabalhos direcionados a avaliação de um ou outro centro urbano e que apresentem proposições de hierarquias a partir de suas características demográficas, econômicas ou sociais, por exemplo (SUPERINTENDÊNCIA DE ESTUDOS ECONOMICOS E SOCIAIS DA BAHIA, 2010).

Diante dessa constatação, e tendo em conta as mudanças na estrutura social e econômica assistidas na Bahia, a partir dos anos 1980, entendeu-se ser oportuno averiguar a dinâmica urbana do estado nas últimas décadas, pensando-se na forma e nos processos que resultaram na produção de sua rede. Eis que surgiram questões a respeito de algumas de suas cidades, em particular sobre aquelas que exercem funções de intermediação. Basicamente, indagou-se: quais são as cidades médias da Bahia? Que papéis desempenham e quais as especificidades funcionais? Este texto pretende constituir-se num ponto inicial para a elaboração de um estudo de maior amplitude, no qual se realizem discussões mais profícuas, que respondam a questionamentos como esses. Nesses termos, sua proposta é a de apresentar critérios para identificar suas cidades médias, o que foi feito considerando distintas vertentes e debates teóricos elaborados por autores que se dedicam ao tema, bem como o perfil da rede urbana baiana. Mais precisamente, a intenção é de elaborar um conceito operacional para essas cidades.

Com essa perspectiva, organizou-se este artigo em quatro itens, além desta introdução. No primeiro, apresentaram-se algumas ideias e conceitos sobre cidade e sua relação com o processo de urbanização engendrado pelo capitalismo. No segundo, elaborou-se uma reflexão sobre a expressão cidade média, com ênfase na questão do tamanho demográfico como princípio para categorizá-la, de acordo com suas características e papéis na rede. Segue-se um item no qual, a partir do que foi tratado anteriormente e de breves comentários sobre a dinâmica urbana da Bahia, há um exercício com vistas a identificação de suas cidades médias. Por fim, teceram-se considerações adicionais sobre o tema, enfatizando a importância em estudá-lo.

Geo UERJ - Ano 15, no. 24, v. 1, $1^{\circ}$ semestre de 2013 p. 285-311

ISSN: 1415-7543 E-ISSN: 1981-9021

http://www.e-publicacoes.uerj.br/index.php/geouerj 


\section{RELAÇÕES ENTRE CIDADE E URBANIZAÇÃO}

O estudo do tema cidade - sua organização interna, elementos de consolidação, papéis em uma dada rede urbana e formas de articulação - não é algo recente na literatura científica. Essa assertiva se comprova, por exemplo, pela densidade do trabalho de Vasconcelos (1999), que analisou, minuciosamente, mais de 300 obras datadas dos séculos XIX e XX, elaboradas no âmbito das distintas ciências, voltadas à compreensão da realidade urbana. Dessa leitura, algo que salta aos olhos é a diversidade de interpretações sobre o que é uma cidade, a variedade de indicações de métodos para avaliá-la e, ainda, para estabelecer os eventos e fatores que mais contribuem para sua formação e definição funcional. Por isso mesmo, o autor advertiu quanto à necessidade de explicar os conceitos considerando os pressupostos sobre os quais foram elaborados, sejam os de bases científica ou aqueles referentes ao contexto temporal e espacial. Depreende-se, pois, que assim como as cidades se distinguem entre si e conforme os movimentos da sociedade no transcurso da história (SANTOS, 2005; CORRÊA, 1989), os conceitos para elas estabelecidos também observam significativas transformações.

Nos últimos anos, frente ao desenvolvimento do meio técnico-científico-informacional - e suas repercussões nos modos de produção, na articulação entre os lugares e, sobretudo, na divisão socioespacial do trabalho - , as discussões em torno do conceito de cidade ganharam novo impulso. Isso porque esse movimento implicou, entre outros, em novas estratégias de produção e uso do espaço. Santos (1999) e Sposito et alli (2007) destacaram que as articulações entre os lugares, há décadas, eram decorrentes, fundamentalmente, da contiguidade. Porém, com o avanço das técnicas, passaram também a ser consequência da conectividade. Desse modo, conteúdos e demandas que tem origem em um determinado ponto do mundo têm a possibilidade de influenciar a organização sócio-espacial de distintos lugares.

Sposito (1999) colocou com bastante propriedade que o desenvolvimento das tecnologias favoreceu o contundente avanço da urbanização — entendida a partir do aumento da população das áreas urbanas, mas, principalmente, como um conteúdo social e cultural que adquiriu um novo rumo com o desenvolvimento do capitalismo industrial. O conteúdo da cidade, por conta das particularidades desse processo, se expandiu para além dos seus limites legalmente estabelecidos. Melhor dizendo, cada vez mais as lógicas e determinações lá produzidas alcançam a todos os lugares. Tal situação decorre do fato de que cidade e urbanização formam um par indissociável, o que se evidencia facilmente na medida em que "[...] a cidade está todo o

Geo UERJ - Ano 15, no. 24, v. 1, $1^{\circ}$ semestre de 2013 p. 285-311

ISSN: 1415-7543 E-ISSN: 1981-9021

http://www.e-publicacoes.uerj.br/index.php/geouerj 
tempo a expressar e sustentar a processo de urbanização, e sob essa perspectiva sintetiza a dinâmica espaço temporal desse processo" (SPOSITO, 1999, p. 85). A mesma pesquisadora acrescentou que a análise desse par possibilita "[...] compreender o espaço urbano como materialidade presente, mas também como processo, como acumulação dos tempos, como expressão das formas como se organizam e reorganizam, tendo em vista a urbanização e suas determinações" (SPOSITO, 1999, p. 86-87). Essa perspectiva, adicionou, se faz possível pelo estudo dos usos do espaço, algo definido por meio das diferentes práticas sociais. É mister asseverar a necessidade da identificação das especificidades de cada parte da cidade e, ao mesmo tempo, suas articulações com outras frações desse mesmo espaço urbano, bem como, a dessa totalidade com os demais espaços urbanos. Trabalhando com esse método, torna-se possível perceber os elementos e processos que constituíram sua espacialidade e, de igual maneira, pode-se compreender o fundamento das mudanças ocorridas nas cidades.

Moura (2009) e Lopes (2009), inquietadas pelos diferentes aspectos dessa nova realidade, empreenderam uma discussão sobre urbano, urbanização e cidade. Analisando diversas proposições e autores, observaram ser impossível pensar a cidade sem falar no urbano, o principal elemento estruturador do espaço, seja ele qual for. Numa dessas observações Moura tomou de empréstimo as ideias de Sposito (2005 apud MOURA, 2009, p. 377) quando afirmou que a "cidade é, concomitantemente, um conceito descritivo, que permite apreender uma realidade material concreta, e um imperativo, pois evoca um conjunto de diversas funções sociais [...]”. Ainda influenciada pelas concepções da aludida autora, Moura (2009) descreveu a urbanização como um processo de longa duração, que se iniciou com o surgimento das primeiras cidades e se revelou a partir dos distintos modos de produção visto que, inequivocamente, representa e favorece a existência da divisão social do trabalho. Corroborando essa ideia com a de outros pesquisadores (SOUZA; LINS, 1999; RODRIGUES, 2007 apud MOURA, 2009), asseverou que o urbano se revela como uma expressão espacial da produção capitalista, que pode ser entendido, na contemporaneidade, como um modo de vida que atinge praticamente toda a sociedade.

Lopes (2009) também entendeu que a urbanização decorrente da industrialização se difundiu amplamente, adquirindo autonomia em relação ao evento que a gerou. Na mesma linha apresentada por Moura (2009), avaliando teses de autores clássicos e contemporâneos, sobretudo a partir das de Souza (1999 apud LOPES, 2009, p. 409), afirmou que "[...] o urbano é um atributo das aglomerações humanas, que nelas se materializa, mas a elas não se limita, dado que é resultado das múltiplas interações sociais e dos modos de ser, pensar e agir derivados de

Geo UERJ - Ano 15, no. 24, v. 1, $1^{\circ}$ semestre de 2013 p. 285-311

ISSN: 1415-7543 E-ISSN: 1981-9021

http://www.e-publicacoes.uerj.br/index.php/geouerj 
viver em locais adensados". Portanto, ainda que com uma abordagem e referencial distintos, a partir dos trabalhos já mencionados, a autora concordou e apresentou uma ideia síntese de que: a urbanização se consolida na cidade, atribuindo-lhe forma e conteúdo, mas, não se restringe a ela.

Discutindo mais propriamente o conceito de cidade, Moura (2009, p. 377) assinalou que se trata do "[...] concreto, o lugar onde vivem os cidadãos, o material, o conjunto de infraestruturas, equipamentos e toda materialidade que permite a vida coletiva de um conjunto de cidadãos coabitando [...]". Nesses termos, é o espaço construído, tendo surgido "[...] como uma unidade social que desempenha um papel privilegiado nas trocas - materiais ou não -, em todas as atividades de direção e de gestão, e no processo inovativo" (MOURA, 2009, p. 378). É onde os vários grupos se encontram, possibilitando coexistência, trocas, e o compartilhamento de um mesmo território. Essa posição se coaduna com a de Sposito (2006, p. 116), para quem a cidade “[...] é espaço propício à realização de atividades que requerem o encontro, proximidade ou possibilidade de comunicação, especialização e complementaridade de papéis".

$\mathrm{Na}$ tentativa de estabelecer um conceito operacional de cidade, Lopes (2009) apontou suas características mais gerais considerando, especialmente, as assertivas de Corrêa (1989) e Souza (2003). Entendeu-a como um espaço urbano socialmente construído, que comporta certo número de habitantes residindo em um aglomerado dotado de algum grau de centralidade econômica, onde se verifica multiplicidade de usos do solo, distintas classes sociais e uma parcela dos residentes ocupada em atividades não agrícolas.

Faz-se relevante acrescentar que, para Corrêa (1989), a grande cidade capitalista é o espaço urbano por excelência e, portanto, sua organização se apresenta como resultado do trabalho social. Na tentativa de apreendê-la, verificou que tal espaço se revela, num primeiro momento, como um conjunto de diferentes usos da terra justapostos entre si, que resultam na fragmentação espacial e na delimitação de áreas distintas. Porém, essas porções da cidade não permanecem isoladas, se articulam por meio dos fluxos materiais e imateriais. Acrescentou que, como produto da ação social, a cidade apresenta em sua estrutura as marcas do desenvolvimento das forças produtivas e, por conseguinte, dos conflitos decorrentes das relações de produção. Nesses termos, é um reflexo da sociedade e, concomitantemente, torna-se um dos condicionantes da dinâmica social. O autor sintetizou suas argumentações da seguinte forma: "eis o que é o espaço urbano: fragmentado e articulado, reflexo e condicionante social, um conjunto de símbolos e

Geo UERJ - Ano 15, no. 24, v. 1, $1^{\circ}$ semestre de 2013 p. 285-311

ISSN: 1415-7543 E-ISSN: 1981-9021

http://www.e-publicacoes.uerj.br/index.php/geouerj 
campo de lutas. É assim a própria sociedade em uma de suas dimensões, aquela mais aparente, materializada nas formas espaciais" (CORRÊA, 1989, p. 9).

Souza (2003) trabalhou com elementos similares. Observando a realidade brasileira verificou que, diferindo do meio rural, da aldeia ou do povoado, as cidades são assentamentos urbanos sobejamente diversificados em termos econômicos e funcionais, e que desempenham o papel de centro de gestão do território. Acrescentou que possuem uma certa centralidade econômica e que sua área de influência pode se circunscrever a seus limites territoriais ou avançar sobre seu entorno imediato, para as cidades vizinhas, ou conforme a dimensão de sua estrutura, comandar uma rede composta por cidades a média e longa distâncias. Destaca-se, nessa abordagem, a importância atribuída à cultura que, assim como o poder, "[...] desempenha um papel crucial na produção do espaço urbano e na projeção da cidade para fora de seus limites físicos" (SOUZA, 2003 , p. 28). Posto isso, afirmou que a cidade não é só local da produção e da gestão, é onde as pessoas se organizam, interagem, “[...] formando grupos de afinidades e de interesses, menos ou mais bem definidos territorialmente, com base na identificação entre certos recursos cobiçados e o espaço, ou na base das identidades territoriais que os indivíduos buscam manter e preservar" (SOUZA, 2003, p. 28).

Todos esses autores convergiram, portanto, no entendimento da cidade como um produto histórico-social, que acumula em sua estrutura as marcas de diferentes modos de produção. Trata-se, como bem descrito por Carlos (2004), do trabalho humano materializado, acumulado ao longo de várias gerações; produto, condição e meio de reprodução social. Pensar sobre essa realidade, portanto, implica necessidade de considerar a sociedade em movimento e, com igual atenção, as práticas cotidianas, verdadeiras construtoras do espaço. De forma instigante a autora colocou que "esta perspectiva ilumina a armadilha da redução do sentido da cidade àquela de condição de reprodução do capital, ou da dominação do Estado, ambas esvaziadas do sentido da vida humana" (CARLOS, 2004, p. 17). Assim, entende-se a cidade como produto históricosocial, como uma realidade material (o que é sua própria dimensão espacial), cuja forma e conteúdo revelam os processos que a consolidaram no decorrer do tempo.

\section{ALGUMAS QUESTÕES SOBRE AS CIDADES MÉDIAS}

A avaliação das reflexões dos autores acima mencionados conduz a ideia de que há um relativo acordo no que tange às características e aos processos que dão forma e conteúdo à cidade. Todavia, a criação de uma definição que dê conta da multiplicidade de dimensões que essa

Geo UERJ - Ano 15, no. 24, v. 1, $1^{\circ}$ semestre de 2013 p. 285-311

ISSN: 1415-7543 E-ISSN: 1981-9021

http://www.e-publicacoes.uerj.br/index.php/geouerj 
realidade comporta é algo que não prima pela simplicidade. Quando o olhar se volta a uma categoria de cidades, a média, essa tarefa se revela ainda mais árdua. De fato, literalmente não há um consenso ou uma concepção cristalizada de cidade média que possa ser utilizada indistintamente nas várias ciências, embora no âmbito de cada uma delas e em diferentes contextos históricos seja possível encontrar algum acordo sobre a matéria.

Para Soares (2005), dada a singularidade e a originalidade que essa categoria possui em relação ao conjunto de cidades, é essencial estabelecer uma definição precisa para o termo cidade média e estudá-la em particular. No entanto, ao mesmo tempo em que se assinala tal necessidade, vem sendo relativamente comum mencionar-se a contundente intensificação do crescimento e da participação dessas cidades na população e economia nacionais. Destaca-se, ainda, a ampliação e transformações de seus papéis e funções. Desse modo, ainda que não haja precisão no seu conceito, essas são reconhecidas por constituírem-se em importantes nós da rede urbana nacional (CORRÊA, 2007), e, por isso mesmo, retornaram à pauta de discussão, ganhando importância no meio técnico e científico e nas instâncias de planejamento (CORRÊA, 2007; AMORIM FILHO; SERRA, 2001). Desse modo, ainda que inexistam conceitos e parâmetros mais exatos que permitam definir mais precisamente essa categoria, suas características principais podem ser percebidas quando se estudam as relações que elas estabelecem com as demais, numa determinada escala.

Sposito (2007), fundamentada em trabalhos de diferentes autores, verificou a necessidade de atenção em relação ao uso das expressões cidade média e cidade de porte médio. Salientando ser comum empregá-las de forma indistinta, ressalvou que a primeira delas aplica-se a espaços que realizam a intermediação entre cidades maiores e menores, ao passo que a segunda se refere ao tamanho demográfico. Por conta disso, mesmo a adoção da expressão cidade média para designar a função dos espaços - nesse caso a de articular centros urbanos de portes distintos incorre no risco de ser pouco apropriada, visto que pode induzir a ideia de tamanho populacional, de hierarquia e de classificação. Apontou, então, a necessidade de um rigor científico mais aprofundado e recomendou aos pesquisadores um esforço a fim de que se defina com a maior precisão possível seu objeto de estudo.

Sua preocupação faz sentido, uma vez que os debates quanto à acepção e o emprego da categoria cidade média, na literatura científica em geral, vem sendo calcada sobremaneira no critério demográfico. Nos anos 1940, por exemplo, uma cidade com mais de 20 mil residentes era chamada de média. Na década de 1970, esse status foi conferido a áreas com no mínimo 100

Geo UERJ - Ano 15, n⿳. 24, v. 1, $1^{\circ}$ semestre de 2013 p. 285-311

ISSN: 1415-7543 E-ISSN: 1981-9021

http://www.e-publicacoes.uerj.br/index.php/geouerj 
mil pessoas. Branco (2007), tendo como base de análise o contexto nacional mais recente, considerou como cidade média aquela cuja população estivesse numa faixa compreendida entre o limite mínimo de 100 mil e o máximo de 350 mil habitantes. Porém, de modo geral, nas últimas décadas, vem sendo corrente classificar como médias as cidades brasileiras com portes populacionais variando entre $100 \mathrm{mil}$ e $500 \mathrm{mil}$ habitantes. Tendo tal perspectiva como referência e ressaltando a necessidade de considerar as especificidades regionais para relacionar um determinado tamanho demográfico à denominação de cidade média, Motta e Mata (2008) excluíram dessa consideração mais geral as regiões Norte e Centro-Oeste, onde, devido às características de seu sistema urbano regional, as cidades com populações variando entre 50 mil a 100 mil habitantes também podem desempenhar as funções de intermediação.

Confere consistência à proposição acima, a argumentação de Santos (2005). De acordo com esse estudioso, para entender a urbanização e o papel das cidades em uma determinada escala geográfica deve-se ter em conta a sociedade tal como se apresenta, mas igualmente o histórico de sua formação, as atividades que nela são realizadas e os objetos de que essas dependem para se efetivar. Na mesma vertente, Souza (2003, p. 24) asseverou que "o singular e o particular devem ser entendidos à luz do que é geral (o que não significa, absolutamente, que apenas o que é geral interessa: é necessário, sempre, analisar as variações, as especificidades e as suas causas, e inclusive considerar os fenômenos singulares)".

Nesses termos, se existe a decisão de adotar o tamanho populacional como indicador para definir as cidades médias compete a cada autor, pesquisador ou formulador de política pública, tendo sempre como referência os processos histórico-sociais que levaram à consolidação da estrutura da rede observada, estabelecer o critério demográfico mais pertinente para seu objeto. Por isso mesmo, e acrescentando que "uma cidade média em uma região pobre, como o Nordeste brasileiro, tenderá a não apresentar comércio e serviços tão diversificados e sofisticados quanto uma cidade de mesmo porte em uma região mais próspera [...]" (SOUZA, 2003, p. 30-31), entende-se que no caso dessa região pode-se, também, de forma geral, categorizar como cidades médias àquelas com o corte populacional oscilando em torno de 50 mil a 100 mil habitantes.

Aprofundando o debate sobre a importância do tamanho para entender o papel de um centro, Amorim Filho e Rigotti (2002, p. 10) assinalaram que "[...] os limites definidores do pequeno e do médio não são universais ou ubíquos [...]” e que "[...] um critério arbitrário como o volume populacional pode implicar em consideráveis modificações durante um dado período de tempo

Geo UERJ - Ano $15, n^{\circ} .24$, v. $1,1^{\circ}$ semestre de 2013 p. 285-311

ISSN: 1415-7543 E-ISSN: 1981-9021

http://www.e-publicacoes.uerj.br/index.php/geouerj 
[...]". Reportando-se a outros atributos peculiares a esse tipo de cidade, concluíram que, “[...] sendo válidos teoricamente tais critérios, nem toda a cidade de porte médio possui as qualidades que podem fazer dela uma cidade funcionalmente média" (op. cit., p. 5). Ademais, "reconhecer uma parcela do território como urbana porque nela se observam níveis de densidade habitacional, pode ser o ponto de partida, mas nunca o ponto de chegada para a análise" (SPOSITO, 2006, p. 113). Dialogando com a perspectiva proposta por esses autores, tem-se que, além do tamanho, há inúmeros parâmetros, como fluxos de relações, séries históricas de crescimento, padrão funcional, entre outros, que se consubstanciam em medidas da importância de um centro em comparação com os demais. Porém, antes de se pensar em categorizar as cidades, convergindo com que foi posto por vários dos que se dedicam a esse tema, afirma-se que a clareza quanto ao objetivo do estudo é fundamental. É a partir dele que devem ser escolhidos os indicadores a serem analisados para caracterizar tais núcleos de modo a agrupálos numa ou noutra categoria.

A preocupação conceitual, outrossim, remete à tentativa de entender, e mesmo superar, as noções mais comumente adotadas para designar cidade média, algo cada vez mais necessária visto que os papéis intermediários na rede urbana têm, progressivamente, se tornado mais complexos e diversificados. Essa situação pode ser vinculada, nos últimos anos, sobretudo, às relações verificadas entre os espaços, cada vez mais intrincadas, e às alterações das formas de produção, que contribuíram firmemente para alteração do raio de influência e da importância dessa categoria. Como ressaltaram Andrade e Serra (1999), Amorim Filho e Serra (2001) e Sposito (2007), desde o final dos anos 1970, quando despontaram processos de desconcentração da produção e da população no país, as cidades médias vêm sendo decisivas na estruturação da rede urbana, isso porque a passagem do modelo fordista para aquele caracterizado pela maior flexibilidade implicou mudanças na divisão regional do trabalho brasileira. Exatamente nesse contexto, houve a ampliação da participação populacional e econômica desse grupo de cidades frente às demais. E, nesse movimento, além da manutenção do seu tradicional papel de elo entre centros maiores e menores, evidenciou-se, nas cidades médias, o estabelecimento de "[...] novos papéis, desenhados por fluxos de outros tipos, orientados por dinâmicas de complementaridade ou concorrência entre cidades da mesma rede ou de redes urbanas diferentes" (SPOSITO et alii, 2007, p. 40).

De qualquer maneira e ainda que seja difícil dar conta de todas variáveis necessárias, não há como escapar ao fato de que, mesmo em sendo uma categoria em construção numa sociedade em acelerada transformação, a determinação de critérios para sua identificação é algo factível.

Geo UERJ - Ano 15, no. 24, v. 1, $1^{\circ}$ semestre de 2013 p. 285-311

ISSN: 1415-7543 E-ISSN: 1981-9021

http://www.e-publicacoes.uerj.br/index.php/geouerj 
Corrêa (2007) avaliou que a particularidade de uma dada cidade (as funções que desempenha na rede) depende de uma combinação específica de três elementos principais: tamanho demográfico, funções urbanas e organização do espaço intraurbano ${ }^{3}$. O aludido pesquisador argumentou que essas características estão intrinsecamente associadas, e que sua análise deve ser feita à luz de uma localização geográfica. Afirmou ainda que, num mesmo contexto regional de renda e padrão cultural, o porte populacional, além de prenunciar as dimensões e estrutura do espaço intraurbano, denota maior ou menor participação na economia, o nível de desenvolvimento das funções urbanas ou das atividades básicas, direcionadas essencialmente para fora da cidade, e não-básicas, destinadas fundamentalmente a atender aos que nela residem.

Amorim Filho (2007) apresentou uma versão mais pormenorizada das particularidades de uma cidade média. Na sua perspectiva, uma cidade que integra essa categoria deve estabelecer intercâmbios constantes e com razoável intensidade, grau de conectividade e qualidade com seu espaço regional e com as aglomerações hierarquicamente superiores; ser capaz de promover a dinamização do espaço rural microrregional que a envolve e apresentar alguma autonomia na geração de parte de seus equipamentos de relações externas. No que tange a morfologia interna, ressaltou como essenciais os seguintes aspectos: presença de um centro relativamente complexo onde respondam-se mais do que as demandas dos habitantes locais; existência de um número razoável de sub-centros, que atendam às necessidades dos seus moradores; e que conte com uma periferia cuja evolução ocorra de forma descontínua espacialmente, e repentina, em termos temporais, o que produz uma estrutura polinucleada. De posse desse rol de elementos, acrescentou que algumas dessas características, de forma geral, variam de uma região para outra, a depender do nível de desenvolvimento, da posição geográfica e das condições históricosociais de formação de cada uma delas. Do mesmo modo, ressaltou que a noção de cidade média não se equivale necessariamente à de centro de polarização regional ou microrregional, visto que as relações das ditas cidades nem sempre implicam dominação de seu entorno, podendo ser de estímulo, dinamização e, em alguns casos, de dependência.

Frente a essa situação, uma definição de cidade média pressupõe o conhecimento e a associação de diversos elementos e critérios, situação que contribui para dificultar um consenso sobre o tema. Ademais, como bem colocou Corrêa (2007, p. 23), além de sua identificação depender dos objetivos da análise e da dimensão da rede em avaliação, “[...] trata-se de discutir uma noção vaga, aberta a múltiplos significados e impregnada de idealismo que a concebe como um ideal a ser alcançado, apresentando as vantagens da pequena cidade sem ter, contudo, as desvantagens da grande". Nessas condições, "conceituar cidade média exige um esforço de

Geo UERJ - Ano 15, n'. 24, v. 1, $1^{\circ}$ semestre de 2013 p. 285-311

ISSN: 1415-7543 E-ISSN: 1981-9021

http://www.e-publicacoes.uerj.br/index.php/geouerj 
abstração, de estabelecer a unidade daquilo que é pouco conhecido, que aparece como muito diversificado" (CORRÊA, 2007, p. 25). Essas questões findam por exigir a construção de conceitos operacionais tanto para a elaboração de estudos acadêmicos quanto para os projetos voltados à aplicação das políticas governamentais.

\section{EXERCÍCIO DE IDENTIFICAÇÃO DAS CIDADES MÉDIAS NA BAHIA}

$\mathrm{Na}$ Bahia, ao longo dos séculos, prevaleceram cidades de tamanho populacional bastante reduzido. Considerando os resultados dos últimos censos demográficos, ainda que se evidencie a propensão em diminuição de sua participação relativa no total estadual, as sedes municipais com tamanhos inferiores a 20 mil habitantes eram predominantes. Em 1980, representavam 91,4\% das existentes no estado e, em 2010, significavam $84,9 \%$ do mesmo total. Todavia, em valores absolutos, aumentou o número desses centros: de 307 passaram a 354, em 1980 e 2010, respectivamente (Tabela 1). É interessante assinalar que entre as cidades de menor tamanho demográfico, o conjunto mais relevante era o que contava com cidades com portes variando entre 5 mil e 10 mil habitantes (em 2010, eram 141 unidades ou 33,8\% do total).

Tabela 1 - Número de sedes municipais por classe de tamanho de população Bahia, 1980 - 2010

\begin{tabular}{|c|c|c|c|c|c|c|c|c|}
\hline \multirow{2}{*}{$\begin{array}{c}\text { Classe de tamanho de } \\
\text { população }\end{array}$} & \multicolumn{4}{|c|}{ Quantidade absoluta } & \multicolumn{4}{|c|}{ Participação relativa } \\
\hline & 1980 & 1991 & 2000 & 2010 & 1980 & 1991 & 2000 & 2010 \\
\hline Acima de 500.000 & 1 & 1 & 1 & 1 & 0,3 & 0,2 & 0,2 & 0,2 \\
\hline De 40.001 a 500.000 & 10 & 23 & 27 & 32 & 3,0 & 5,5 & 6,5 & 7,7 \\
\hline de 100.001 a 500.000 & 3 & 5 & 9 & 11 & 0,9 & 1,2 & 2,2 & 2,6 \\
\hline de 50.001 a 100.000 & 5 & 9 & 11 & 12 & 1,5 & 2,2 & 2,7 & 2,9 \\
\hline de 40.001 a 50.000 & 2 & 9 & 7 & 9 & 0,6 & 2,2 & 1,7 & 2,2 \\
\hline De 20.001 a 40.000 & 18 & 15 & 25 & 30 & 5,4 & 3,6 & 6,0 & 7,2 \\
\hline Inferior a 20.000 & 307 & 376 & 362 & 354 & 91,4 & 90,6 & 87,2 & 84,9 \\
\hline de 10.001 a 20.000 & 32 & 61 & 71 & 80 & 9,5 & 14,7 & 17,1 & 19,2 \\
\hline de 5.001 a 10.000 & 65 & 95 & 125 & 141 & 19,3 & 22,9 & 30,1 & 33,8 \\
\hline de 1.000 a 5.000 & 184 & 203 & 162 & 131 & 54,8 & 48,9 & 39,0 & 31,4 \\
\hline inferior a 1.000 & 26 & 17 & 4 & 2 & 7,7 & 4,1 & 1,0 & 0,5 \\
\hline Bahia & 336 & 415 & 415 & 417 & 100,0 & 100,0 & 100,0 & 100,0 \\
\hline
\end{tabular}

Fonte: IBGE. Censos Demográficos de 1980, 1991, 2000 e 2010.

Já aquelas com os maiores contingentes populacionais, no período em questão, cresceram sucessivamente em termos absolutos e proporcionais. Ainda assim, tinham uma presença pouco expressiva no estado. Com mais de 500 mil residentes, só havia uma cidade, a capital, Salvador ${ }^{4}$. Tendo como referência as sedes municipais cujos portes oscilavam entre 40 mil e 500 mil moradores, existiam 10, em 1980, e 32, em 2010. Em consequência, nesses anos, sua participação relativa, ainda que permanecesse pequena, elevou-se de 3,0\% para 7,7\%,

Geo UERJ - Ano 15, no. 24, v. 1, $1^{\circ}$ semestre de 2013 p. 285-311

ISSN: 1415-7543 E-ISSN: 1981-9021

http://www.e-publicacoes.uerj.br/index.php/geouerj 
correspondentemente. Note-se que, no último ano censitário, com 100 mil e 500 mil moradores, verificava-se tão somente 11 ou 2,6\% cidades na Bahia. Entre essas, duas estavam na Região Metropolitana de Salvador (RMS): Camaçari e Lauro de Freitas. Em outras porções do estado, tinha-se Feira de Santana, Vitória da Conquista, Itabuna, Juazeiro, Ilhéus, Jequié, Alagoinhas, Teixeira de Freitas e Barreiras. Considerando que aqueles centros localizados nas regiões metropolitanas estão, de forma geral, integrados à dinâmica da metrópole e, por isso, não desempenham funções de intermediação (BRANCO, 2007; SANTOS, 2009), esse último grupo, composto pelos não metropolitanos, como vários estudos sobre o estado apontaram, efetivamente possuem centralidade, papéis e estrutura que lhes conferem a condição de cidade média, nos moldes da discussão anteriormente realizada.

Acrescenta-se que, além de quantitativamente reduzidos, os centros urbanos mais proeminentes em termos populacionais estavam localizados, principalmente, ao longo da costa oceânica da Bahia e relativamente próximos ou mesmo nos seus limites político-administrativos (Figura 1). Desse modo, numa grande parcela do estado, especialmente na parte central do semiárido, inexistiam sedes de maiores proporções demográficas, cujo tamanho, denotasse, a priori, possibilidade de realizar atividades compatíveis com o papel de intermediação.

Da observação da Tabela 1 e da Figura 1, tem-se, pois, a permanência de uma reduzida proporção de municípios com tamanhos demográficos significativos. Depreende-se, também, que subsistem, ainda atualmente, fenômenos que resultaram em dinâmicas urbanas particulares às regiões litorânea, fronteiriça e central. Em relação a elas pode-se vislumbrar que, além das peculiaridades dos processos que lhes deram origem, muito possivelmente, há distinções no que concerne aos papéis que são capazes de exercer na rede, bem como, na forma como se articulam com as demais.

A localização dos maiores centros, é necessário assinalar, encontra raízes nos processos históricos de concentração da população e das estruturas produtivas estaduais, na antiga vinculação de sua economia ao modelo agroexportador e na forma pela qual a Bahia foi inserida na lógica da divisão regional do trabalho quando da difusão da industrialização no país. Conforme averiguado por Dias, Araújo e Vidal (2011), as distintas políticas de desenvolvimento direcionadas ao Nordeste, bem como, aquelas que presidiram a dinâmica de redistribuição da economia verificadas, sobretudo, a partir dos anos 1990 - que efetivamente colaboraram para a alteração do papel e importância de alguns municípios na rede urbana estadual - não tiveram grande repercussão no que tange à ampliação do número de unidades com maior porte populacional, vale dizer, na melhor distribuição da população no território baiano.

Geo UERJ - Ano 15, no. 24, v. 1, $1^{\circ}$ semestre de 2013 p. 285-311

ISSN: 1415-7543 E-ISSN: 1981-9021

http://www.e-publicacoes.uerj.br/index.php/geouerj 
Nesses termos, faz-se necessário lembrar que, tal como proposto por Corrêa (2007), Motta e Mata (2008), M. Santos (2005), Amorim Filho (2007) e J. Santos (2009), entre outros, a compreensão da importância do tamanho demográfico deve ser avaliada considerando o contexto ou a rede em que um determinado centro está inserido. Reforçando tal ideia, adicionase que para Michel (1977 apud AMORIM FILHO, 2007, p. 71), “[...] os níveis populacionais que balizam as cidades médias devem pertencer às categorias intermediárias no conjunto total das cidades da região de que fazem parte". Ademais, “[...] aspectos ligados às funções de intermediação dentro de redes urbanas, assim como à posição geográfica da aglomeração são tão ou mais importantes do que o tamanho demográfico na caracterização das cidades médias" (AMORIM FILHO, 2007, p. 73).

Figura 1 - População residente nas sedes municipais da Bahia em 2010 


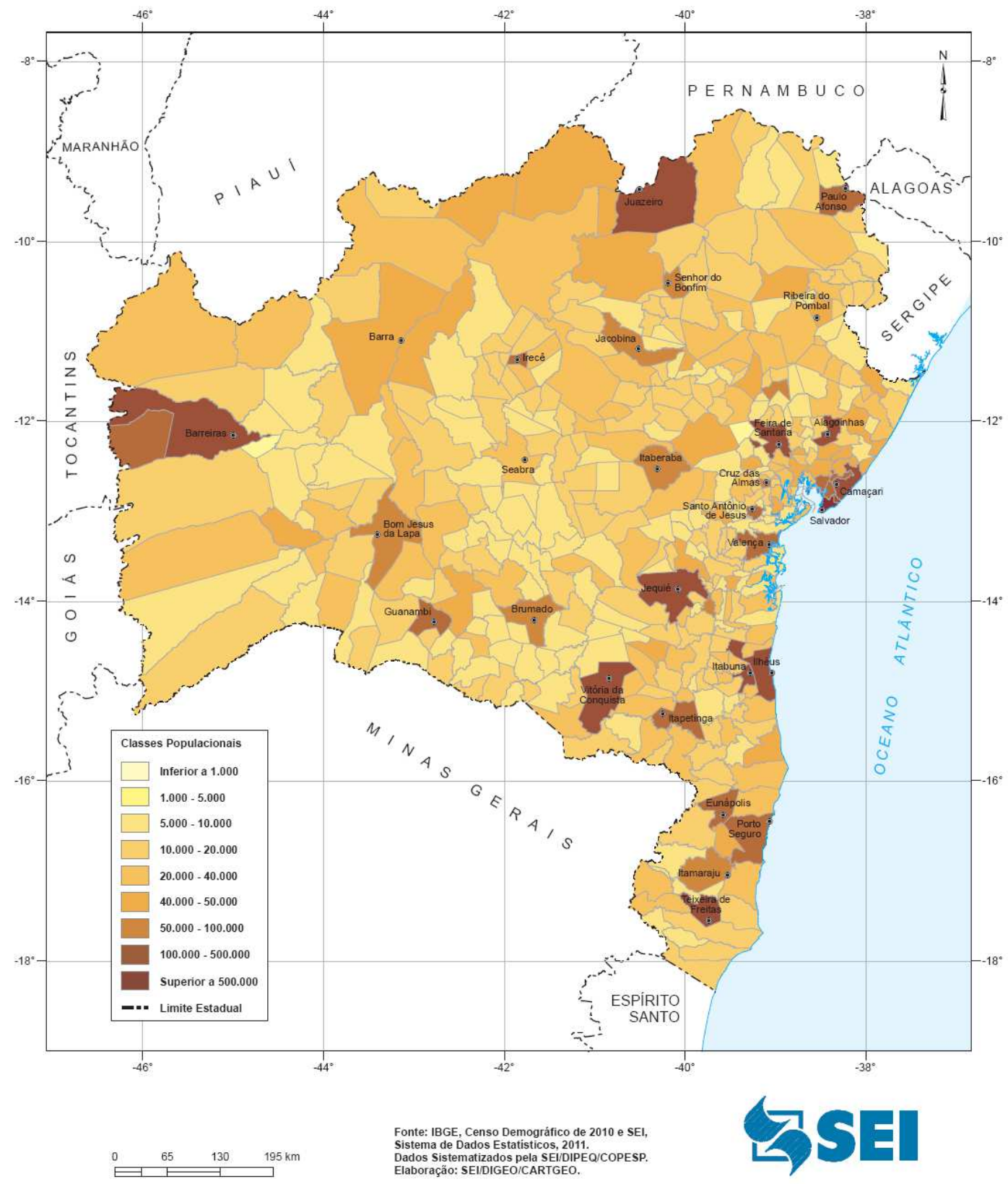

Com base em tais teses, avaliando as condições histórico-sociais de consolidação da rede urbana da Bahia, o padrão de distribuição da população e a localização de seus maiores núcleos urbanos, preliminarmente, e a título de operacionalizar uma investigação sobre a dinâmica do estado, supôs-se que também exerçam papel de intermediação entre cidades com dessemelhantes cortes demográficos e posições hierárquicas, sedes municipais com populações inferiores a 100 mil habitantes, normalmente, o "limite máximo" para categorizar uma cidade como média no Brasil.

Geo UERJ - Ano 15, no. 24, v. 1, $1^{\circ}$ semestre de 2013 p. 285-311

ISSN: 1415-7543 E-ISSN: 1981-9021

http://www.e-publicacoes.uerj.br/index.php/geouerj 
Propõe-se, a partir dos elementos acima citados, ter como referencia para identificar as cidades médias baianas um tamanho de população igual ou superior a 40 mil habitantes e igual ou inferior a 500 mil habitantes. Esse patamar mínimo tem como base a população média das cidades baianas, em 2010 - uma referência importante conforme alguns dos autores citados neste texto - , algo em torno de 23 mil habitantes. Ademais, reforçando a ideia da construção de um objeto de estudo qualificado, considerou-se que tal papel se evidenciaria ainda por meio da expressão de um nível de centralidade que estaria além de seu entorno imediato.

Em relação a esse último critério, o nível de centralidade, na ausência de estudos mais recentes e aprofundados sobre a rede urbana baiana, adotou-se como principal parâmetro para identificá-lo o trabalho intitulado Regiões de Influência das Cidades, o Regic, de 2007 (INSTITUTO BRASILEIRO DE GEOGRAFIA E ESTATÍSTICA, 2008) ${ }^{5}$. Tal opção decorreu da convergência de seus resultados com os de pesquisas efetivadas, entre os anos 1980 e início dos 1990, sobre a dinâmica urbana estadual ${ }^{6}$, bem como, com trabalhos feitos, principalmente nas universidades, sobre algumas regiões e municípios do estado.

Com o propósito de discutir as características e as funções das cidades médias da Bahia, portanto, estabeleceu-se como pressuposto metodológico básico para sua identificação, os seguintes atributos: (i) registrar população oscilando entre 40 mil e 500 mil habitantes, conforme os resultados do Censo Demográfico de 2010; (ii) não estar localizada na RMS; e (iii) se apresentar na condição de capital regional ou centro sub-regional de acordo com o Regic, de 2007. Em relação a tal trabalho, cabe ainda pontuar que se entende ser provável a existência de cidades baianas que não estejam nessas categorias, mas, que se constituam em cidades médias. Para reconhecê-las cabe uma avaliação mais detalhada de suas características e localização.

Aplicada esse primeiro conjunto de condições, partiu-se para a avaliação da posição geográfica de tais centros em relação aos demais e às principais vias de circulação do estado, verificando-se em qual das tradicionais regiões baianas (litoral, semiárido e oeste) se localizavam.

Cabem algumas ponderações adicionais em relação ao corte demográfico aqui adotado, pouco usual em estudos de âmbito nacional ou regional. A primeira diz respeito ao fato de que o tamanho populacional deve ser entendido como uma referência e, para pensar em cidade média, deve-se considerar um porte que reflita a média da escala em análise. Uma segunda relaciona-se às especificidades da formação da rede urbana da Bahia, estado que conta com cerca de $60 \%$ do seu território no semiárido. Sua difícil e tardia ocupação, a histórica falta de políticas públicas que efetivamente permitissem o desenvolvimento dos seus municípios vis a vis os processos que

Geo UERJ - Ano 15, no. 24, v. 1, $1^{\circ}$ semestre de 2013 p. 285-311

ISSN: 1415-7543 E-ISSN: 1981-9021

http://www.e-publicacoes.uerj.br/index.php/geouerj 
ocorreram nas porções litorâneas e fronteiriças resultaram na permanência de população rarefeita numa vasta porção daquela área. Note-se ainda que, no semiário, entre aqueles municípios que revelaram importância econômica e demográfica, em tempos pretéritos, poucos ainda guardam centralidade e participação populacional ou econômica de destaque.

Essa situação pode ser captada, por exemplo, pela leitura de um trabalho elaborado no âmbito da Superintendência de Estudos Econômicos e Sociais da Bahia (1997). Tendo em conta a participação na produção, no contingente populacional e papel na articulação dos fluxos verificou-se que, no final dos anos 1990, 28 cidades exerciam um papel de "liderança" na rede urbana baiana. Subdivididas em dois grupos por ordem de importância, destacou-se a rede urbana principal, tal como seus autores chamaram, formada pelas sedes municipais de Salvador, Feira de Santana, Itabuna, Camaçari, Vitória da Conquista, Ilhéus, Paulo Afonso, Juazeiro, Alagoinhas e Barreiras. E a rede secundária, também com grande relevância na organização territorial do estado, era composta por Jequié, Santo Antônio de Jesus, Guanambi, Jacobina, Teixeira de Freitas, Eunápolis, Senhor do Bonfim, Itapetinga, Santo Amaro, Valença, Porto Seguro, Serrinha, Cruz das Almas, Brumado, Irecê, Itamaraju, Bom Jesus da Lapa e Itaberaba.

Chama-se atenção para algumas das conclusões daquele trabalho, a exemplo da avaliação da maior densidade das redes formadas pelos centros do litoral o que se trata do "[...] reflexo da circulação realizada entre o Centro-Sul e Nordeste, com ênfase em Salvador, e a produção agrícola ou agro-industrial das suas mediações" (SUPERINTENDÊNCIA DE ESTUDOS ECONÔMICOS E SOCIAIS DA BAHIA, 1997, p. 122). Igualmente, ressalta-se que as rodovias federais e/ ou estaduais - BR-101, BR-116 e BR-415/BA-263 - faziam-se fundamentais à circulação e à concepção de uma rede de cidades comerciais. Comparando a organização e as possibilidades de articulação dessas sedes municipais litorâneas àquelas mais relevantes do "miolo da Bahia", notou-se que as últimas achavam-se mais isoladas no território e estavam menos articuladas entre si. Ademais, de forma geral, as relações dessas cidades com aquelas que estavam sob sua influência caracterizavam-se, fundamentalmente, pela dependência.

De fato, a análise de diferentes trabalhos, que tratam de questões referentes à dinâmica urbana baiana, indica que mesmo que no semiárido estejam cerca de 260 municípios, destacavam-se pelo papel na articulação dos fluxos estaduais apenas Guanambi, Irecê, Jacobina, Bom Jesus da Lapa, Itaberaba e Senhor do Bonfim (SUPERINTENDÊNCIA DE ESTUDOS ECONÔMICOS E SOCIAIS DA BAHIA, 2010).

Geo UERJ - Ano 15, no. 24, v. 1, $1^{\circ}$ semestre de 2013 p. 285-311

ISSN: 1415-7543 E-ISSN: 1981-9021

http://www.e-publicacoes.uerj.br/index.php/geouerj 
Retornando à questão do tamanho populacional, verificou-se que 32 sedes municipais baianas registraram entre 40 mil e 500 mil habitantes, em 2010. Entre essas, cinco estavam na RMS Lauro de Freitas, Camaçari, Simões Filho, Candeias e Dias d'Ávila - o que as exclui da possibilidade de serem cidades médias.

Relacionando a informação de porte demográfico aos resultados do Regic 2007, mais seis cidades não apresentavam características compatíveis com o que aqui foi estabelecido para definir as cidades médias do estado. Porto Seguro, Itapetinga, Itamaraju, Serrinha e Ipiaú, que foram classificadas como centro de zona, e Luís Eduardo Magalhães. Esta última, que contava com 54.881 citadinos, estava na categoria de centro local, embora, nos últimos anos, tenha se destacado pela dinâmica econômica. As demais, respondiam a demandas de um restrito grupo de centros urbanos e estavam no âmbito de influência de outros núcleos que, tradicionalmente, desempenham papéis de polo regional.

Nesses termos, pela articulação dos indicadores proposta, ter-se-iam, então, 21 cidades médias. Todavia, em 6 de julho de 2011, por meio de Lei Complementar, foi instituída a Região Metropolitana de Feira de Santana (RMFS). A partir daquela data, oficialmente, Feira de Santana foi colocada na condição de metrópole. Evidentemente, tal condição, na práxis, não passa do atendimento a fins político-administrativos. Tendo em conta tal fato - ainda que se questione se seu perfil e características a coloquem nessa categoria - os dados do Censo Demográfico de 2010 e os do Regic 2007, decidiu-se considerar como cidades médias apenas as sedes municipais de Vitória da Conquista, Itabuna, Juazeiro, Ilhéus, Barreiras (capitais regionais), Jequié, Teixeira de Freitas, Alagoinhas, Eunápolis, Paulo Afonso, Santo Antônio de Jesus, Valença, Irecê, Guanambi, Senhor do Bonfim, Cruz das Almas, Itaberaba, Jacobina, Brumado e Bom Jesus da Lapa (classificados como centros sub-regionais) (Tabela 2).

Tabela 2 - População total, urbana, da sede municipal e rural de 2010 dos municípios, classificação segundo o Regic de 2007 e localização das cidades médias da Bahia Bahia, 2007 e 2010

Geo UERJ - Ano $15, n^{\circ} .24$, v. $1,1^{\circ}$ semestre de 2013 p. 285-311

ISSN: 1415-7543 E-ISSN: 1981-9021

http://www.e-publicacoes.uerj.br/index.php/geouerj 


\begin{tabular}{|c|c|c|c|c|c|c|}
\hline \multirow[b]{2}{*}{ Município } & \multicolumn{4}{|c|}{ População absoluta } & \multirow[b]{2}{*}{ REGIC } & \multirow[b]{2}{*}{ Localização } \\
\hline & Total & Urbana & $\begin{array}{c}\text { Sede } \\
\text { municipal }\end{array}$ & Rural & & \\
\hline \multicolumn{7}{|c|}{ Capital Regional } \\
\hline Vitória da Conquista & 306.866 & 274.739 & 260.260 & 32.127 & Capital Regional B & Semiárido e fronteiriço \\
\hline Itabuna & 204.667 & 199.643 & 199.643 & 5.024 & Capital Regional B & Litoral \\
\hline Juazeiro & 197.965 & 160.775 & 151.336 & 37.190 & Capital Regional C & Semiárido e fronteiriço \\
\hline Ilhéus & 184.236 & 155.281 & 148.557 & 28.955 & Capital Regional B & Litoral \\
\hline Barreiras ${ }^{(1)}$ & 137.427 & 123.741 & 123.741 & 13.686 & Capital Regional C & Oeste e fronteiriço \\
\hline \multicolumn{7}{|c|}{ Centro Sub-regional } \\
\hline Jequié & 151.895 & 139.426 & 136.470 & 12.469 & Centro Sub-regional A & Semiárido \\
\hline Teixeira de Freitas ${ }^{(2)}$ & 138.341 & 129.263 & 128.482 & 9.078 & Centro Sub-regional A & Litoral \\
\hline Alagoinhas & 141.949 & 124.042 & 122.281 & 17.907 & Centro Sub-regional B & Litoral \\
\hline Eunápolis & 100.196 & 93.413 & 93.413 & 6.783 & Centro Sub-regional B & Litoral \\
\hline Paulo Afonso ${ }^{(3)}$ & 108.396 & 93.404 & 93.404 & 14.992 & Centro Sub-regional A & Semiárido e fronteiriço \\
\hline Santo Antônio de Jesus & 90.985 & 79.299 & 79.299 & 11.686 & Centro Sub-regional A & Litoral \\
\hline Valença & 88.673 & 64.368 & 59.476 & 24.305 & Centro Sub-regional B & Litoral \\
\hline Irecê & 66.181 & 61.019 & 58.350 & 5.162 & Centro Sub-regional A & Semiárido \\
\hline Guananbi & 78.833 & 62.565 & 58.111 & 16.268 & Centro Sub-regional A & Semiárido \\
\hline Senhor do Bonfim & 74.419 & 57.566 & 49.975 & 16.853 & Centro Sub-regional B & Semiárido \\
\hline Cruz das Almas & 58.606 & 49.885 & 49.885 & 8.721 & Centro Sub-regional B & Litoral \\
\hline Itaberaba & 61.631 & 48.485 & 48.485 & 13.146 & Centro Sub-regional B & Semiárido \\
\hline Jacobina & 79.247 & 55.868 & 47.587 & 23.379 & Centro Sub-regional A & Semiárido \\
\hline Brumado & 64.602 & 45.131 & 43.955 & 19.471 & Centro Sub-regional B & Semiárido \\
\hline Bom Jesus da Lapa & 63.480 & 43.099 & 41.555 & 20.381 & Centro Sub-regional B & Semiárido \\
\hline Ribeira do Pombal & 47.518 & 29.756 & 29.756 & 17.762 & Centro Sub-regional B & Semiárido \\
\hline \multicolumn{7}{|c|}{ Centro de Zona } \\
\hline Seabra & 41.798 & 20.277 & 19.535 & 21.521 & Centro de Zona A & Semiárido \\
\hline
\end{tabular}

Fonte: IBGE. Censo Demográfico de 2010 e REGIC 2007. SEI. Sistema de Dados Estatísticos, 2011.

Notas: (1) De acordo com os resultados do regic 2007, este município, e aqueles que são por ele polarizados, integra tanto a rede de Salvador quanto a de Brasília (Metrópole Nacional).

(2) De acordo com os resultados do regic 2007, este município, assim como aqueles por ele polarizados, integra a rede comandada por Vitória, capital do Espírito Santo, classificada como Capital Regional A.

(3) De acordo com os resultados do regic 2007, este município, assim como aqueles por ele polarizados, compõe a rede de Aracaju, capital de Sergipe, classificada como Capital Regional A. Essa, por sua vez, integra a rede de influencia de Salvador.

A observação da localização desses municípios no território baiano (Tabela 2 e Figura 2) permite algumas constatações adicionais. Evidencia-se que as principais cidades do litoral estão mais próximas e conectadas por vias de circulação do que as das demais regiões baianas. Outra nota plausível é a de que a rede formada no entorno da capital é a mais densa. Do mesmo modo, a permanência de um relativo vazio de cidades potencialmente capazes de realizar o papel de intermediação no centro do semiárido, bem como, na sua porção nordeste levanta a hipótese de que cidades menores tenham importância na articulação dos centros dessas regiões, caso de Seabra, no semiárido, e Ribeira do Pombal, no nordeste.

Figura 2 - Localização das cidades médias da Bahia e classificação segundo o Regic de 2007

Geo UERJ - Ano 15, no . 24, v. 1, $1^{\circ}$ semestre de 2013 p. 285-311

ISSN: 1415-7543 E-ISSN: 1981-9021

http://www.e-publicacoes.uerj.br/index.php/geouerj 


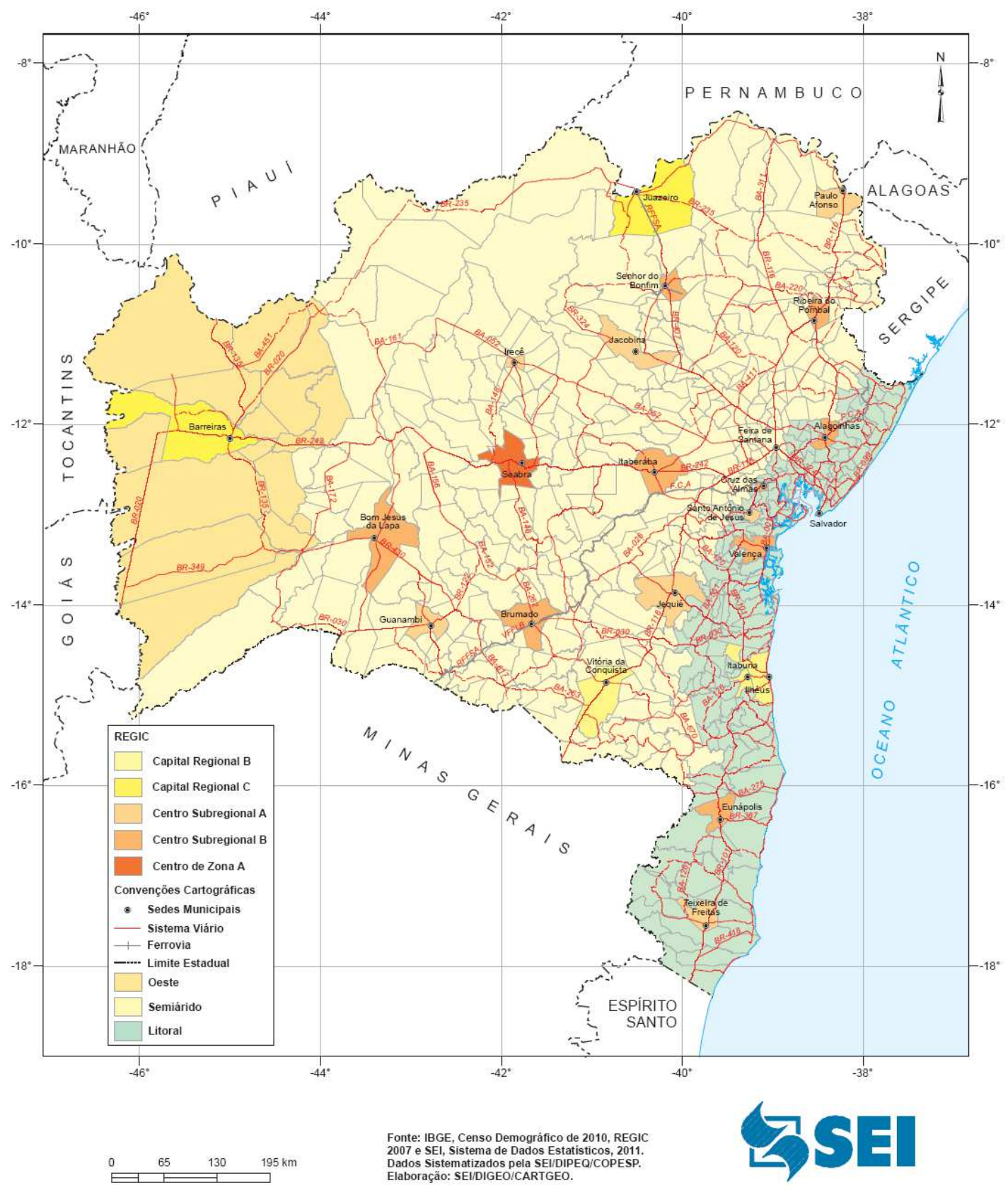

Além da referida observação do mapa, a hipótese de que essas integram a categoria cidade média assenta-se no fato de que, embora registrassem a população da sede inferior ao corte demográfico aqui adotado, tinham, de acordo com o Regic 2007, como centro imediatamente superior a capital e polarizavam, cada uma, um grupo formado por cerca de 10 cidades. Acrescente-se que, embora, Seabra tivesse classificada como centro de zona, Ribeira do Pombal, fora reconhecida como centro sub-regional. Nesses termos, optou-se por incluí-las nessa categoria, ainda que se considere que caiba avaliar com maior detalhamento suas características e papéis na rede, ao longo das últimas décadas.

Geo UERJ - Ano 15, nº. 24, v. 1, $1^{\circ}$ semestre de 2013 p. 285-311

ISSN: 1415-7543 E-ISSN: 1981-9021

http://www.e-publicacoes.uerj.br/index.php/geouerj 
Nesses termos, utilizando-se os elementos, acima mencionados, associados aos levantamentos bibliográficos sobre o tema, é pertinente argumentar que as cidades que possuem papéis significativos de intermediação na rede urbana da Bahia são: Vitória da Conquista, Itabuna, Juazeiro, Ilhéus, Barreiras, Jequié, Teixeira de Freitas, Alagoinhas, Eunápolis, Paulo Afonso, Santo Antônio de Jesus, Valença, Irecê, Guanambi, Senhor do Bonfim, Cruz das Almas, Itaberaba, Jacobina, Bom Jesus da Lapa, Seabra e Ribeira do Pombal (Tabela 2). Todavia, assinala-se que para entender com maior propriedade sua função na estruturação do espaço estadual cabem estudos mais apurados para verificar o grau e a intensidade das relações dessas cidades com as demais de sua rede e sua relevância econômica. Do mesmo modo, deve-se investigar a organização dos seus espaços intraurbanos e o efeito que a proximidade existente, entre algumas delas, pode ter para limitar seu raio de influência.

\section{CONSIDERAÇÕES ADICIONAIS}

O que se pode considerar como verdade nos discursos sobre o tema cidades médias? Uma primeira resposta possível se refere à inexistência de um consenso no que tange ao seu conceito. No entanto, a relativa convergência em relação aos atributos que as caracterizam, possibilita sua identificação e a formulação de conceitos operacionais, estabelecidos em conformidade com os propósitos daqueles que tomam essa categoria como objeto de estudo. Uma segunda observação diz respeito ao fato de que, ainda que normalmente acompanhado de outras informações e de algumas ponderações, o tamanho demográfico vem sendo o critério mais frequentemente aplicado para reconhecê-las. Uma terceira, que pode ser extraída das várias referências sobre o tema, está associada a sua função: as cidades médias, ou como muitos a nomeiam, intermediárias, têm desempenhado papel de núcleo estratégico nas redes urbanas, constituindo elos entre o espaço urbano e o regional. Uma quarta resposta pertinente: o crescimento do número de cidades que participam dessa categoria e sua importância na dinâmica socioeconômica brasileira vêm sendo cada vez mais significativos.

É possível, desse modo, fazer algumas afirmações sobre as características das cidades médias. Destaca-se a necessidade de pensá-las como unidades articuladas a um sistema de cidades, com capacidade de adensar fluxos e relações materiais e imateriais. Igualmente, a que se considerar que são dotadas de um nível de centralidade que extrapola seu entorno próximo e que apresentam capacidade de conferir complexidade a funções e papéis específicos. Por isso mesmo, e frente às possibilidades engendradas pelo desenvolvimento do meio técnicocientífico-informacional, tendem a ampliar a abrangência de sua rede, caracterizada, no presente, tanto pela contiguidade como pela conectividade (SANTOS, 1999).

Geo UERJ - Ano 15, n'. 24, v. 1, $1^{\circ}$ semestre de 2013 p. 285-311

ISSN: 1415-7543 E-ISSN: 1981-9021

http://www.e-publicacoes.uerj.br/index.php/geouerj 
Pensando-se na Bahia, nos processos que resultaram na configuração de sua rede e em suas cidades médias, sabendo-se que a sociedade brasileira tem passado por constantes transformações e que seus múltiplos espaços vêm mudando intensa e rapidamente de papéis e de posição em diferentes sistemas urbanos, cabem algumas indagações. Que dinâmicas e agentes sociais foram responsáveis pela consolidação da estrutura de sua rede urbana? O que a caracteriza e que papéis suas cidades médias vem assumindo nas últimas décadas? Que diferenças e semelhanças há entre as cidades médias baianas? Como vivem e sobrevivem seus habitantes? Em que medida suas características se aproximam ou distanciam daquelas localizadas nos demais estados brasileiros? E mais, concordando com as questões colocadas por Corrêa (2007, p. 33) e aplicando-as à realidade estadual, "qual a natureza, intensidade e alcance espacial das relações econômicas das cidades médias? [...] qual o destino da cidade média?”.

Sem a pretensão de responder aqui a tais indagações (que foram apresentadas com o intuito de apontarem problemas de pesquisa), assevera-se que para avançar nessa avaliação é preciso ter como pressuposto que as cidades médias não podem ser mais tratadas apenas como o foram em outros contextos históricos - ou seja, como núcleos de contenção de demandas e de fluxos migratórios que se dirigiam aos grandes centros - , mas, como espaços capazes de contribuir, por meio de implementação de ações governamentais, para a redução das desigualdades regionais.

Nesses termos, entre os papéis que tendem a desempenhar hodienarmente, há que se considerar e fortalecer a possibilidade de se constituírem em núcleo de apoio e de polo de serviços a aglomerações menores, o que implica na provável criação de oportunidades para melhoria das condições de vida dos cidadãos que nelas residem, daqueles que estejam no entorno rural, ou mesmo dos que morem em municípios próximos. Dessa maneira, entende-se que, embora com uma perspectiva distinta da tradicional, "[...] hoje como outrora, as cidades médias continuam a ser valorizadas como um fator de equilíbrio para as redes e hierarquias urbanas de muitos países, principalmente aqueles em que a dissimetria entre as cidades grandes e pequenas é mais forte" (AMORIM FILHO; SERRA, 2001, p. 27).

Outrossim, nas últimas décadas, há que se evidenciar a condição assumida pelas cidades médias, de eixos de transportes e de desenvolvimento. Tornaram-se, pois, dada a sua posição geográfica e na rede urbana, núcleos de dinamização do crescimento regional dada sua capacidade de realizar a articulação entre os espaços, uma função que nem pode ser muito concentrada (nas poucas grandes cidades) tampouco excessivamente dispersa (nos inúmeros pequenos centros urbanos). Essa característica retroalimenta sua tradicional função de "pivô de articulação" e

Geo UERJ - Ano 15, no. 24, v. 1, $1^{\circ}$ semestre de 2013 p. 285-311

ISSN: 1415-7543 E-ISSN: 1981-9021

http://www.e-publicacoes.uerj.br/index.php/geouerj 
confere-lhe a capacidade de atrair atividades que prescindem da aglomeração, em especial aquelas referentes à inovação tecnológica.

Por isso mesmo, tais cidades vêm se apresentando como locais atrativos ao capital industrial, nacional ou estrangeiro. Dita atração, via de regra, tem ocorrido por determinadas condições ofertadas por essa categoria de cidades, seja em termos da infraestrutura urbana e dos custos da instalação. Uma dessas condições decorre dos custos associados à menor aglomeração em relação às áreas situadas mais próximas às metrópoles; outra se relaciona a sua posição geográfica, normalmente estratégica, para a circulação.

Essa atratividade ao capital industrial traz a perspectiva de ampliação da produção e da oferta de empregos, e a consequente demanda por equipamentos comerciais e de serviços cada vez mais especializados e qualificados. Por isso, as cidades médias passaram a se constituir, também, em lugares propícios a implantação de empreendimentos imobiliários destinados às pessoas com maior poder aquisitivo. Essa situação pode se refletir ainda na ampliação do mercado consumidor, na maior sofisticação dos serviços prestados, mas, igualmente, no aumento da pobreza e na consolidação de processos de segregação sócio-espacial, algo que vem sendo discutido por diversos pesquisadores.

Tendo em vista principalmente a possibilidade dissociação territorial entre o lugar de gestão/comando/controle (cada vez mais centralizado espacialmente nas metrópoles) e o lugar da produção industrial (desconcentrado ao longo do território) — viabilizado pelo avanço das técnicas - é mister asseverar os novos papéis urbanos assumidos por várias cidades médias brasileiras, marcando mudanças na sua estrutura e nos fluxos que articulam. Nessa óptica, sua distribuição e papel na rede urbana devem ser avaliados tendo-se em mente as dinâmicas intrarregionais, as lógicas que repercutiram em sua localização e as especificidades históricas e funcionais dos lugares. Mas, sobretudo, devem-se considerar os processos de divisão social e espacial do trabalho.

Porém, a par de todas as argumentações e constatações, a pergunta que orienta esse debate é: por que estudar as cidades médias? Por que identificar e discutir as cidades médias baianas?

Segundo Corrêa (2007), seja na esfera do planejamento seja na da academia, tal iniciativa tem como mérito representar um esforço de síntese em torno de uma noção que ainda não foi solidamente construída em nenhum desses âmbitos. Em relação ao planejamento, ressaltou que, embora em outros tempos tivesse sido objeto de políticas específicas, a falta de base teórica relacionada ao conhecimento do tema rede urbana vem impossibilitando sua análise de forma

Geo UERJ - Ano 15, n $^{\circ} .24$, v. 1, $1^{\circ}$ semestre de 2013 p. 285-311

ISSN: 1415-7543 E-ISSN: 1981-9021

http://www.e-publicacoes.uerj.br/index.php/geouerj 
mais consistente e, em decorrência, a construção de ações particulares para essa categoria de cidades pensadas, no âmbito dessa rede, em relação às demais.

No que tange a academia, de acordo com o mesmo autor, também se requer o avanço na questão. Tal se justifica pela necessidade de estimular um debate mais amplo em torno do tema cidade média, o que inclui a aproximação de um conceito mais consensual. Com esse propósito, Corrêa (2007) sugeriu a realização de estudos de casos; comparativos; ou ainda os exploratórios.

Tentando aliar o viés teórico ao empírico, portanto, e concordando com as ideias aqui apresentadas, procurou-se responder a questão acima. Partiu-se do entendimento de que, de forma geral, a estrutura das cidades e mesmo a dinâmica da urbanização respondem às alterações resultantes da divisão social e espacial do trabalho. Além disso, acredita-se que a cidade é principalmente espaço de vida, de encontro, do cotidiano, e que cada lugar guarda especificidades condizentes com sua produção ao longo da história. Desse modo, para que se possa pensar em políticas públicas a elas aplicáveis, torna-se fundamental verificar suas especificidades e funções na rede (em relação as maiores e as menores unidades) e conhecer sua organização intraurbana.

Pensando-se propriamente na Bahia, estado que possui uma rede urbana marcada pela assimetria entre seus centros, pela extrema concentração populacional, pela dispersão e pouca articulação dos seus maiores centros, onde convivem formas modernas e tradicionais de produção, tem-se que, inicialmente, compreender a dinâmica e as características de suas cidades médias constituem uma estratégia para propor ações com vistas a minimizar as desigualdades sócio-espaciais. Considera-se, fundamentalmente, que estudá-las significa buscar compreender o papel de uma porção importante do território, a partir do qual se pode atender às demandas de uma parcela significativa da população, proporcionando condições de elaboração de políticas para obtenção de melhores investimentos (em termos de volume e de especificidades) e, consequentemente, de dinamização socioeconômica de um determinado espaço regional e de melhoria das condições de vida dos seus cidadãos.

1 As autoras agradecem a contribuição de Rosa Moura, técnica do Instituto Paranaense de Desenvolvimento Econômico e Social (IPARDES), pelas críticas, sugestões e questionamentos que nortearam este trabalho, ao tempo em que a isentam de quaisquer equívocos porventura cometidos.

2 Este artigo foi originalmente publicado no número 119 da Revista Paranaense de Desenvolvimento, editada pelo IPARDES, relativa ao período jul./dez. 2010.

3 Para Corrêa (2007, p. 33), tamanho demográfico, funções urbanas e organização do espaço intraurbano são aspectos que, combinados de formas específicas, permitem categorizar uma cidade como pequena, média, grande ou metrópole. Porém, considerou que esses elementos não são suficientes para a construir

Geo UERJ - Ano 15, no. 24, v. 1, $1^{\circ}$ semestre de 2013 p. 285-311

ISSN: 1415-7543 E-ISSN: 1981-9021

http://www.e-publicacoes.uerj.br/index.php/geouerj 
o objeto cidade média. "O pressuposto da conexão entre tamanho demográfico, funções urbanas e espaço intraurbano pode ser contestado. Mais que isto, parece ser necessário incluir outros elementos que podem afetar a organização interna da cidade, a saber, entre outros, o sítio da cidade, o plano urbano, a natureza das atividades básicas, a renda da população, a antiguidade da cidade e a natureza das políticas públicas locais".

4 Em 2010, assim como ocorre desde 1960, apenas a cidade de Salvador registrou contingente superior a 500 mil habitantes.

5 No Regic 2007, as capitais regionais foram caracterizadas como aquelas "com capacidade de gestão no nível imediatamente inferior ao das metrópoles, tem área de influência de âmbito regional, sendo referidas como destino, para um conjunto de atividades, por um grande número de municípios" (INSTITUTO BRASILEIRO DE GEOGRAFIA E ESTATÍSTICA, 2008, p. 11). Aos centros subregionais foram atribuídas as seguintes peculiaridades: serem centros de gestão de atividades menos complexas, terem área de atuação mais reduzida e terem, de forma geral, relacionamentos com centros externos a sua rede reduzidos às três metrópoles nacionais (São Paulo, Rio de Janeiro e Brasília).

6 Como mencionado na introdução deste trabalho, as pesquisas a que se faz referência tinham como resultado, normalmente, a hierarquização dos municípios a partir de um ou mais indicadores.

\section{Referências}

AMORIM FILHO, Oswaldo Bueno. Origens, evolução e perspectivas dos estudos sobre cidades médias. In: SPOSITO, Maria Encarnação Beltrão (Org.). Cidades médias: espaços em transição. São Paulo: Expressão Popular, 2007. p. 69-87.

AMORIM FILHO, Oswaldo Bueno; RIGOTTI, José Irineu Rangel. Os Limiares Demográficos na Caracterização das Cidades Médias. In: Encontro da Associação Brasileira de Estudos Populacionais, 8., 2002, Ouro Preto. Anais... Ouro Preto: ABEP, 2002. p. 1-22. Disponível em: <http://www.abep.nepo.unicamp.br/docs/anais/pdf/2002/GT_MIG_ST25_Amorim_texto.pdf>. Acesso em: 31 jan. 2008.

AMORIM FILHO, Oswaldo Bueno; SERRA, Rodrigo Valente. Evolução e perspectivas do papel das cidades médias no planejamento urbano e regional. In: ANDRADE, Thompson Almeida; SERRA, Rodrigo Valente (Orgs.). Cidades médias brasileiras. Rio de Janeiro: IPEA, 2001. p. 1-34.

ANDRADE, Thompson Almeida; SERRA, Rodrigo Valente. O recente desempenho das cidades médias no crescimento populacional urbano brasileiro. Revista Brasileira de Estudos de População. Campinas: ABEP: IBGE: IPEA, vol. 6, n. 1/2, jan./dez. 1999. p. 12-49.

BRANCO, Maria Luisa Gomes Castello. Algumas considerações sobre a identificação de cidades médias. In: SPOSITO, Maria Encarnação Beltrão (Org.). Cidades médias: espaços em transição. São Paulo: Expressão Popular, 2007. p. 89-111.

CARLOS, Ana Fani Alessandri. O espaço urbano. Novos escritos sobre a cidade. São Paulo: Contexto, 2004.

CORRÊA, Roberto Lobato. Construindo o conceito de cidade média. In: SPOSITO, Maria Encarnação Beltrão (Org.). Cidades médias: espaços em transição. São Paulo: Expressão Popular, 2007. p. 23-33.

Geo UERJ - Ano 15, no. 24, v. 1, $1^{\circ}$ semestre de 2013 p. 285-311

ISSN: 1415-7543 E-ISSN: 1981-9021

http://www.e-publicacoes.uerj.br/index.php/geouerj 
O espaço urbano. São Paulo: Ática, 1989.

DIAS, Patricia Chame; ARAÚJO, Mayara Mychella Sena; VIDAL, Francisco Baqueiro. Principais municípios da Bahia: considerações sobre sua dinâmica populacional. Bahia Análise \& Dados, Salvador, v. 21, n. 2, jan./abr. 2011, p. 351-370.

INSTITUTO BRASILEIRO DE GEOGRAFIA E ESTATÍSTICA. Regiões de influência das cidades: 2007. Rio de Janeiro: IBGE, 2008.

LOPES, Diva Maria Ferlin. Cidades pequenas são urbanas? O urbano possível. Bahia Análise \& Dados, Salvador, v. 19, n. 2, jul./set. 2009, p. 395-412.

MOTTA, Diana; MATA, Daniel. Crescimento das cidades médias. Boletim Regional Urbano. Brasília: IPEA, n. 1, dez. 2008, p. 33-38. Disponível

http://www.ipea.gov.br/sites/000/2/publicacoes/bru/bru_01.pdf. Acesso em: 28/07/2010.

MOURA, Rosa. A cidade em transformação: processos, conceitos e novos conteúdos. Bahia Análise \& Dados, Salvador, v. 19, n. 2, jul./set. 2009, p. 377-393.

SANTOS, Janio. Urbanização e produção de cidades na Bahia: reflexões sobre os processos de estruturação e reestruturação urbana. Bahia Análise \& Dados, Salvador, v. 19, n. 2, jul./set. 2009, p. 499-509.

SANTOS, Milton. A natureza do espaço. Técnica e tempo. Razão e emoção. 3. ed. São Paulo: Hucitec, 1999.

SANTOS, Milton. A divisão social do trabalho como uma nova pista para o estudo da organização espacial e da urbanização nos países subdesenvolvidos. In: SANTOS, Milton. $D a$ totalidade ao lugar. São Paulo: EDUSP, 2005. p. 55-75

SOARES, Beatriz Ribeiro. Cidades médias: uma revisão bibliográfica. In: ALVES, A. F.; FLÁVIO, L. C.; SANTOS, R. A. (Orgs.) Espaço e território: interpretações e perspectivas do desenvolvimento. Francisco Beltrão: UNIOESTE, 2005. p. 273-285.

SOUZA, Marcelo Lopes de. ABC do desenvolvimento urbano. Rio de Janeiro: Bertrand Brasil, 2003.

SPOSITO, Maria Encarnação Beltrão. Sobre novas possibilidades e perspectivas: historiando nosso percurso e apresentando nossos textos sobre cidades médias. In: SPOSITO, Maria Encarnação Beltrão (Org.). Cidades médias: espaços em transição. São Paulo: Expressão Popular, 2007. p. 9-20.

SPOSITO, Maria Encarnação Beltrão et alii. O estudo das cidades médias brasileiras: uma proposta metodológica. In: SPOSITO, Maria Encarnação Beltrão (Org.). Cidades médias: espaços em transição. São Paulo: Expressão Popular, 2007. p 35- 67.

SPOSITO, Maria Encarnação Beltrão. A questão campo-cidade: perspectivas a partir da cidade. In: SPOSITO, Maria Encarnação Beltrão. WHITACKER, Arthur Magon (Orgs.). Cidade e campo: relações e contradições entre o urbano e o rural. São Paulo: Expressão Popular, 2006. p. 111-130.

SPOSITO, Maria Encarnação Beltrão. A urbanização da sociedade. Reflexões para um debate sobre as formas espaciais. In: DAMIANI, Amélia Luísa; CARLOS, Ana Fani Alessandri;

Geo UERJ - Ano 15, nº. 24, v. 1, $1^{\circ}$ semestre de 2013 p. 285-311

ISSN: 1415-7543 E-ISSN: 1981-9021

http://www.e-publicacoes.uerj.br/index.php/geouerj 
SEABRA, Odette Carvalho de Lima (Orgs.). O espaço no fim do século. A nova raridade. São Paulo: Contexto, 1999. p. 83-99.

SUPERINTENDÊNCIA DE ESTUDOS ECONÔMICOS E SOCIAIS DA BAHIA.

Referênciais para a análise da dinâmica urbana do estado da Bahia 1998-2008: relatório II. Salvador: SEI, 2010. 122 p. Projeto Rede Urbana do Brasil e da América do Sul. Pesquisa Dinâmica Urbana dos Estados.

. Cidades da Bahia. Salvador: SEI, 1997 (Série Estudos e pesquisas, 35).

VASCONCELOS, Pedro de Almeida. Dois séculos de pensamento sobre a cidade. Editus: Ilhéus, 1999.

Artigo recebido para publicação em maio de 2013.

Artigo aceito para publicação em maio de 2013. 